\title{
Efeito ergogênico da cafeína na performance em exercícios de média e longa duração
}

\author{
Leandro Altimari ${ }^{1,2}$ \\ Juliana de Melo $^{1,3}$ \\ Michele Trindade ${ }^{1,2}$ \\ Julio Tirapegui ${ }^{1,2}$ \\ Edilson Cyrino ${ }^{1}$
}

https://doi.org/10.5628/rpcd.05.01.87

\section{RESUMO}

A cafeína é uma substância que não apresenta valor nutricional, sendo classificada como um alcalóide farmacologicamente ativo, estimulante do sistema nervoso central (SNC). No entanto, esta substância tem sido considerada um ergogênico nutricional, por estar presente em várias bebidas consumidas diariamente, tais como o café, o chocolate, o mate e algumas bebidas à base de guaraná. O seu uso tem se tornado bastante comum no meio esportivo, principalmente nos últimos anos, particularmente por atletas que disputam provas de ciclismo e corredores de média e longa distância. O efeito ergogênico da cafeína sobre a performance tem sido demonstrado após a ingestão aguda de doses de cafeína entre 3 e $6 \mathrm{mg} / \mathrm{kg}$ de peso corporal. Contudo, ainda não parece estar claro quais os mecanismos de ação da cafeína que estariam envolvidos na melhoria da performance em exercícios prolongados. Quanto ao suposto efeito diurético provocado pelo uso da cafeína, este não tem sido confirmado na prática e, ao que parece, está relacionado ao emprego de mega-doses desta substância. Recentemente, a cafeína foi retirada da lista de substâncias proibidas pela Agência Mundial Anti-Doping (WADA), o que possivelmente implicará em um aumento considerável do uso desta substância por parte de atletas. Assim, é necessário que se tome alguns cuidados quando da utilização desta substância ergogênica, uma vez que a ingestão desorientada pode contribuir para o aparecimento de efeitos colaterais que poderão influenciar negativamente a performance do atleta.

Palavras-chave: cafeína, doping, ergogênico nutricional, performance, exercícios físicos prolongados.

\author{
${ }^{1}$ Grupo de Estudo e Pesquisa em Metabolismo, Nutrição e \\ Exercício, Centro de Educação Física e Desportos, \\ Universidade Estadual de Londrina, Paraná, Brasil \\ ${ }^{2}$ Departamento de Alimentos e Nutrição Experimental, \\ Faculdade de Ciências Farmacêuticas, Universidade de São \\ Paulo, São Paulo, Brasil \\ ${ }^{3}$ Departamento de Ciência do Esporte, Faculdade de Educação \\ Física, Universidade de Campinas, São Paulo, Brasil
}

\author{
ABSTRACT \\ Ergogenic effect of caffeine on performance in middle- \\ and long- term exercise
}

Caffeine is a substance that does not have a nutritional value being classified as a pharmacological active alkaloid, with stimulating action on central nervous system (CNS). However, this substance has been considered a nutritional ergogenic, since it is present in several drinks consumed daily, such as coffee, chocolate, teas and some soft drinks with guaraná. Its use has been common in sports, specially in last years, particularly for athletes in cycling competitions and middle- and long-distance runners. The ergogenic effect of caffeine on performance has been demonstrated after the acute ingestion of doses of caffeine between 3 and $6 \mathrm{mg} / \mathrm{kg}$ of body weight. However, it is not still clear which action mechanisms of caffeine would be involved on performance improvement of long-term exercise. The supposed diuretic effect induced by the use of caffeine has not been confirmed in practice, and it seems that it is related to employment of mega-doses of this substance. Recently, caffeine was removed of the list of the prohibited substances by the World Agency Anti-Doping (WADA). This probably implies a considerable increase of its use by athletes. Thus, it is necessary some cares when using this ergogenic substance, since the disoriented ingestion may contribute to the emergence of collateral effects influencing negatively athlete's performance.

Key Words: caffeine, doping, nutritional ergogenic, performance, longterm exercise. 


\section{INTRODUÇÃO}

$\mathrm{Na}$ busca do sucesso esportivo de alto nível, treinadores, nutricionistas, médicos e cientistas têm lançado mão de inúmeros recursos ergogênicos no intuito de potencializar a performance ou atenuar os mecanismos geradores de fadiga de seus atletas $(52,60)$. A fadiga é apontada como fator limitante da performance e constitui um fenômeno complexo ou até mesmo um conjunto de fenômenos de interação simultânea com diferentes graus de influência, dependendo da natureza do exercício físico (14). Nesse sentido, a utilização de suplementos nutricionais como recursos ergogênicos tem se mostrado eficiente por retardar o aparecimento da fadiga e aumentar o poder contrátil do músculo esquelético e/ou cardíaco, aprimorando, portanto, a capacidade de realizar trabalho físico, ou seja, a performance atlética $(4,20,53,61,66)$.

A cafeína, embora não apresente qualquer valor nutricional, tem sido considerada por alguns pesquisadores um ergogênico nutricional, por estar presente em vários produtos comerciais consumidos diariamente $(2,39,78)$. Assim sendo, a cafeína tem sido utilizada com grande freqüência como substância ergogênica de forma aguda, previamente à realização de exercícios físicos, com o intuito de protelar a fadiga e, conseqüentemente, aprimorar a performance, sobretudo em atividades de média e longa duração $(1,11,40,43,52,63)$.

Até final do ano de 2003 a cafeína aparecia na lista de substâncias proibidas pela Agência Mundial AntiDoping (WADA), na classe de estimulantes (A). Mais recentemente, a WADA retirou a cafeína da lista de substâncias proibidas, incluindo esta em uma lista de substâncias que serão monitoradas a partir de 2004 (93).

\section{CAFEÍNA}

A cafeína (1,3,7 - trimetilxantina) é um derivado da xantina, quimicamente relacionada com outras xantinas: teofilina (1,3 - dimetilxantina) e teobromina (3,7 - dimetilxantina) que se diferenciam pela potência de suas ações farmacológicas sobre o sistema nervoso central (SNC) (37) (Figura 1). Nesse sentido, a cafeína é uma substância capaz de excitar ou restaurar as funções cerebrais e bulbares sem, contudo, ser considerada uma droga terapêutica, sendo comumente utilizada e livremente comercializada, por apresentar uma baixa capacidade de indução à dependência $(12,76)$.<smiles>CN1C(=O)N(C)C(O)c2c1ncn2C</smiles>

CAFEINA $1,3,7$ trimetilxantina<smiles>Cn1c(=O)c2[nH]cnc2n(C)c1=O</smiles>

TEOFILINA 1,3 dimetilxantina<smiles>Cn1cnc2c1c(=O)[nH]c(=O)n2C</smiles>

TEOBROMINA 3,7 dimeil xantina

Figura 1. Estrutura química da cafeína e metilxantinas relacionadas.

Nos últimos anos a cafeína tem sido utilizada como substância ergogênica, de forma aguda, previamente à realização de exercícios físicos, particularmente em atividades de média e longa duração $(76,77,78,81)$. Ela tem sido considerada um ergogênico nutricional por estar presente em vários produtos consumidos diariamente, como o guaraná, o mate, o chocolate, o café, alguns refrigerantes e chás, embora não apresente qualquer valor nutricional $(2,40,78)$. A cafeína também vem sendo classificada como uma droga, pois é caracterizada por efeitos farmacológicos de ação estimulante, podendo ser encontrada em alguns medicamentos como agente para antagonizar o efeito calmante de certos fármacos $(14,37,76)$. A Tabela 1 apresenta as quantidades de cafeína presentes em alguns produtos comerciais e as respectivas concentrações excretadas na urina. 
Tabela 1. Concentração de cafeína em produtos comerciais e o seu respectivo nível de excreção.

\begin{tabular}{|c|c|c|}
\hline Produto & $\begin{array}{l}\text { Ouantidade } \\
\text { [mg] }\end{array}$ & $\begin{array}{c}\text { Excreção } \\
\text { após } 2 \cdot 3 \mathrm{hs} \\
(\mu \mathrm{g} / \mathrm{ml})\end{array}$ \\
\hline 1 Copo de café (240 ml) & $100,0\left[^{*}\right]$ & 1,50 \\
\hline Chá instantâneo [150 ml] & $28,0\left[^{*}\right]$ & 0,42 \\
\hline Chá natural preparado $(150 \mathrm{ml}]$ & $20,0 \cdot 110,0$ & $0,30 \cdot 1,60$ \\
\hline $\begin{array}{l}1 \text { lata de Coca Cola, Coca Diet } \\
\text { (330 ml) }\end{array}$ & 45,6 & 0,68 \\
\hline $\begin{array}{l}1 \text { lata de Pepsi, Pepsi Diet } \\
\text { (330 ml] }\end{array}$ & 36,0 & 0,54 \\
\hline Milk shake de chocolate $(30 \mathrm{~g}$ ) & 6,0 & 0,08 \\
\hline Chocolate amargo-barra [ $30 \mathrm{~g}$ ] & 20,0 & 0,30 \\
\hline Chocolate em Pó $[30 \mathrm{~g}$ ) & 26,0 & 0,40 \\
\hline 1 Nodoz & 100,0 & 1,50 \\
\hline 1 Vivarin & 200,0 & 3,00 \\
\hline 1 Anacin & 32,0 & 0,48 \\
\hline 1 Excedrin & 65,0 & 0,97 \\
\hline 1 Midol & 32,4 & 0,48 \\
\hline
\end{tabular}

Adaptado de Allen, $\varepsilon$ \& Hanburys, AF (1992). Athletic drug reference '96. apud Fuentes, RJ; Rosenberg, JM; Davis, A. Durham: Clean Data, 1996, p.25.

( ${ }^{*}$ Teor médio, está na dependência do modo de preparo.

A utilização indiscriminada de cafeína por parte de atletas, no início da década de 1980, com objetivo de melhorar a performance, fez com que esta substância fosse incluída na lista de substâncias proibidas pelo Comitê Olímpico Internacional $(76,77)$. Contudo, o uso de cafeína somente tornou-se evidente a partir dos Jogos Olímpicos de Los Angeles (1984), quando alguns membros da equipe de ciclismo dos Estados Unidos declararam publicamente terem usado esse alcalóide como estimulante durante as competições (71).

O uso dessa substância tem se tornado mais comum nos últimos anos, particularmente por atletas que disputam provas de ciclismo e corredores de média e longa distância $(1,51,52)$.

Até final do ano de 2003 a cafeína constava na lista de substâncias proibidas pela WADA, na classe de estimulantes (A). Entretanto, mais recentemente, a WADA retirou a cafeína da lista de substâncias proibidas, incluindo esta em um programa de monitoramento, o qual será feito por meio de acompanhamento na incidência de detecção do uso de cafeína pelos atletas (93).

\section{ABSORÇÃO, METABOLIZAÇÃO E EXCREÇÃO}

A cafeína é absorvida rapidamente e eficientemente, através do trato gastrointestinal, após administração oral. A mesma parece não afetar as funções gastrointestinais quando ingerida de forma conjugada a diferentes soluções líquidas, como o carboidrato e a água $(76,85)$. Esta substância pode alcançar o pico de concentração máxima na corrente sangüínea entre 15 e 120 minutos após a sua ingestão (76).

A administração desta substância pode ser feita de diversas formas, dentre as quais destacamos a administração intraperitoneal, injeções subcutânea ou intramuscular e também através da aplicação de supositórios $(76,89)$. Sua ação pode atingir todos os tecidos, pois o seu carreamento é feito via corrente sangüínea, sendo posteriormente degradada e excretada pela urina na forma de co-produtos $(14,76,77)$. O metabolismo da cafeína ocorre em maior proporção no fígado, onde existe uma maior concentração de citocromo P450 1A2, enzima responsável pelo metabolismo desta substância $(54,76)$. A metabolização começa com a remoção do grupo metil 1 e 7 , catalizada pelo citocromo P450 1A2, o que possibilita a formação de três grupos metilxantina (31). Em humanos, a maior parte do metabolismo da cafeína ocorre pela mudança na posição do grupo metil 1,3,7 possibilitando uma metabolização com predominância $(84 \%)$ na forma de paraxantina (1,7-dimetilxantina), seguida de teofilina (1,3-dimetilxantina) e de teobromina (3,7-dimetilxantina), sendo esses dois últimos metabolizados em menor quantidade (31, 54) (Figura 2). Os três metabólitos têm demonstrado ser ativos biologicamente $(31,76)$. 


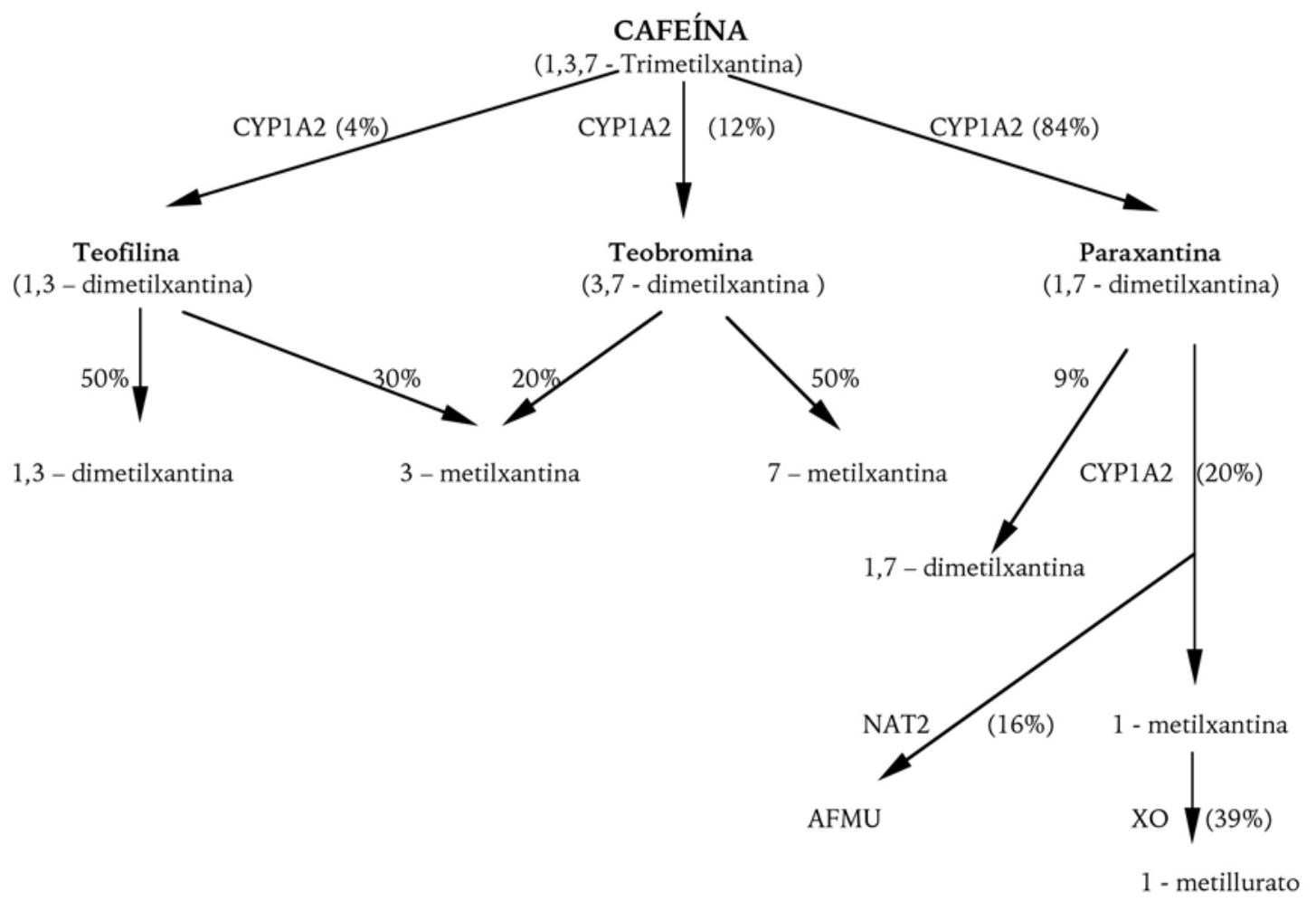

Figura 2. Metabolismo da cafeína em humanos. (Os números dentro dos parênteses são os percentuais do composto metabolizado (CYP $1 A 2$ - citocromo P450; NAT2 - N-acetiltransferase; XO - xantina oxidase; AFMU - 5-acetillamina-6-formilamina-3-metiluracil) (Adaptado de Sinclair \& Geiger, 76).

Embora a maior parte do metabolismo da cafeína ocorra no fígado, outros tecidos, incluindo o cérebro e o rim, têm um importante papel na produção de citocromo $\mathrm{P} 450$ 1A2, e assim têm participação no metabolismo da cafeína (76).

Apesar de apenas uma pequena quantidade de cafeína ser excretada ( 0,5 a $3 \%)$, sem alteração na sua constituição química, sua detecção na urina é relativamente fácil (14). Vale ressaltar que alguns fatores como a genética, a dieta, o uso de alguma droga, o sexo, o peso corporal, o estado de hidratação, o tipo de exercício físico praticado e o consumo habitual de cafeína podem afetar o metabolismo da cafeína e, conseqüentemente, influenciar na quantidade de cafeína total excretada pela urina $(26,76,77)$.

\section{MECANISMOS DE AÇÃO E PERFORMANCE}

Acredita-se que a cafeína possua mecanismos de ação central e periférica que podem desencadear relevantes alterações metabólicas e fisiológicas, as quais melhorariam a performance $(33,43,44,45,77)$ Dessa forma, tem sido proposto pelo menos duas teorias que podem tentar explicar o efeito ergogênico da cafeína durante o exercício físico de média e longa duração $(43,63,77,81)$.

A primeira envolve o efeito direto da cafeína em alguma porção do sistema nervoso central, afetando a percepção subjetiva de esforço e/ou a propagação dos sinais neurais entre o cérebro e a junção neuromuscular $(37,77,92)$. Contudo, essa hipótese é ainda extremamente especulativa, haja vista as grandes limitações que envolvem esse tipo de investigação. A segunda teoria diz respeito ao aumento na oxidação das gorduras e redução na oxidação de carboidratos $(\mathrm{CHO})$. Acreditava-se que a cafeína poderia gerar um aumento na mobilização dos ácidos graxos livres dos tecidos e/ou nos estoques intramusculares (92). Esse efeito, supostamente, ocorreria de maneira indireta por meio do aumento na produção de catecolaminas na circulação, particularmente a epi- 
nefrina, ou diretamente antagonizando os receptores de adenosina (24), um importante regulador do metabolismo lipídico, que normalmente inibem a mobilização dos ácidos graxos livres (AGLs), aumentando a oxidação da gordura muscular e reduzindo a oxidação de $\mathrm{CHO}(19,43,77)$.

Bellet et al. (8) foram os primeiros a documentar o efeito positivo da cafeína sobre o metabolismo, estimulando a mobilização de gorduras (AGLs). Tal efei- to, associado à economia na depleção de glicogênio muscular, acarretou aprimoramento da performance nos exercícios prolongados, sendo posteriormente confirmado por outros estudos $(19,29,48,67)$. A partir daí, muitos foram os estudos que procuraram investigar os possíveis efeitos deste ergogênico sobre a performance em exercícios de média e longa duração (Tabela 2).

Tabela 2. Efeitos ergogênicos da cafeína sobre a performance em exercícios de média e longa duração.

\begin{tabular}{|c|c|c|c|c|c|c|c|}
\hline Investigadores & $\mathrm{N}$ & Sexo & População & $\begin{array}{l}\text { Dose de } \\
\text { cafeína }\end{array}$ & Tipo de teste & $\begin{array}{l}\text { Efeito } \\
\text { ergogênico? }\end{array}$ & Comentários \\
\hline $\begin{array}{l}\text { Alves et al. } \\
(1995)^{3}\end{array}$ & 8 & M & Não-treinados & $10 \mathrm{mg} / \mathrm{kg}$ & $\begin{array}{l}\text { Cicloergômetro a } 80 \% \text { do } \\
\mathrm{VO}_{2} \text { máx até a exaustão }\end{array}$ & Não & $\begin{array}{l}\text { Não se constatou melhora } \\
\text { no desempenho físico }\end{array}$ \\
\hline $\begin{array}{l}\text { Bell \& Mclellan } \\
(2003)^{?}\end{array}$ & 9 & M & Não-treinados & $\begin{array}{l}2,5 \text { e } 5 \\
\mathrm{mg} / \mathrm{kg} \\
\text { [2x dia, } \\
\text { manhã e } \\
\text { tarde]. }\end{array}$ & $\begin{array}{l}\text { Cicloergômetro a } 80 \% \text { do } \\
\mathrm{V0}_{2} \text { máx até a exaustão [ } 2 \\
\text { x dia, manhã e tarde] }\end{array}$ & Sim & $\begin{array}{l}\text { Aumento significante no } \\
\text { tempo de exaustão no } \\
\text { período da manhã e tarde }\end{array}$ \\
\hline Bell et al. $(1998)^{6}$ & 12 & M & Não-treinados & $5 \mathrm{mg} / \mathrm{kg}$ & $\begin{array}{l}\text { Cicloergômetro a } 85 \% \text { do } \\
\mathrm{VO}_{2} \text { máx até a exaustão }\end{array}$ & Não & $\begin{array}{l}\text { Não se constatou melhora } \\
\text { no tempo de exaustão. }\end{array}$ \\
\hline $\begin{array}{l}\text { Berglund \& } \\
\text { Hemmingsson } \\
(1982)^{9}\end{array}$ & 14 & $\begin{array}{l}9 \mathrm{M} \\
5 \mathrm{~F}\end{array}$ & Treinados & $6 \mathrm{mg} / \mathrm{kg}$ & $\begin{array}{l}\text { Corrida sob baixa ( } 300 \\
\text { m) e alta altitude }[2900 \\
\text { m) em intensidades } \\
\text { equivalentes a } 11,5 \mathrm{~km} / \mathrm{h} \\
\text { e } 23,1 \mathrm{~km} / \mathrm{h}\end{array}$ & Sim & $\begin{array}{l}\text { Melhora significante no } \\
\text { desempenho de corrida sob } \\
\text { alta altitude }[2,19 \% \text { para } \\
\text { baixa e } 3,18 \% \text { para alta } \\
\text { intensidade }] \text {. }\end{array}$ \\
\hline $\begin{array}{l}\text { Butts \& Crowell } \\
(1985)^{10}\end{array}$ & 27 & $\begin{array}{l}13 \\
M \\
15 F\end{array}$ & Não-treinados & $300 \mathrm{mg}$ & $\begin{array}{l}\text { Cicloergômetro a } 75 \% \text { do } \\
\mathrm{VO}_{2} \text { máx até exaustão }\end{array}$ & Não & $\begin{array}{l}\text { Aumento não-significante } \\
\text { no tempo de exaustão para } \\
\text { os homens }(14,4 \%) \text { e para } \\
\text { as mulheres }(3,1 \%) \text {. }\end{array}$ \\
\hline
\end{tabular}


Tabela 2. Efeitos ergogênicos da cafeína sobre a performance em exercícios de média e longa duração (continuação).

\begin{tabular}{|c|c|c|c|c|c|c|c|}
\hline Investigadores & $\mathrm{N}$ & Sexo & População & $\begin{array}{l}\text { Dose de } \\
\text { cafeína }\end{array}$ & Tipo de teste & $\begin{array}{l}\text { Efeito } \\
\text { ergogênico? }\end{array}$ & Comentários \\
\hline $\begin{array}{l}\text { Cadarette et al. } \\
(1983)^{13}\end{array}$ & 13 & $\begin{array}{l}8 \mathrm{M} \\
5 \mathrm{~F}\end{array}$ & Não-treinados & $\begin{array}{l}0 ; 2,2 ; 4,4 ; \\
8,8 \\
\mathrm{mg} / \mathrm{kg}\end{array}$ & Corrida de longa duração & Sim & $\begin{array}{l}\text { Aumento significante no } \\
\text { tempo de corrida com a } \\
\text { ingestão de } 4,4 \mathrm{mg} / \mathrm{kg}\end{array}$ \\
\hline $\begin{array}{l}\text { Casal \& Leon } \\
(1985)^{15}\end{array}$ & 9 & M & Treinados & $400 \mathrm{mg}$ & $\begin{array}{l}\text { Corrida em esteira a } 75 \% \text { do } \\
\mathrm{VO}_{2} \text { máx durante } 45 \mathrm{~min} \text {. }\end{array}$ & Sim & $\begin{array}{l}\text { Redução significante na } \\
\text { percepção subjetiva de } \\
\text { esforço e aumento na } \\
\text { concentração de AGL e } \\
\text { lactato. }\end{array}$ \\
\hline $\begin{array}{l}\text { Cohen et al. } \\
(1996)^{16}\end{array}$ & $\begin{array}{l}5 \\
2\end{array}$ & $\begin{array}{l}M \\
F\end{array}$ & Treinados & 5 e $9 \mathrm{mg} / \mathrm{kg}$ & $\begin{array}{l}21 \mathrm{~km} \text { de corrida em } \\
\text { estrada, em ambiente } \\
\text { quente e úmido }\end{array}$ & Não & $\begin{array}{l}\text { Não se constatou melhora } \\
\text { no tempo de corrida nas } \\
\text { dosagens de } 5 \text { e } 9 \mathrm{mg} / \mathrm{kg} \text {. }\end{array}$ \\
\hline $\begin{array}{l}\text { Cole et al. } \\
(1996)^{17}\end{array}$ & 10 & M & Não-treinados & $6 \mathrm{mg} / \mathrm{kg}$ & $\begin{array}{l}\text { Cicloergômetro a } \\
\text { intensidades de } 9,12 \text { e } 15 \\
\text { na escala de Borg [ } 3 \times 10 \\
\text { minutos] }\end{array}$ & Sim & $\begin{array}{l}\text { Aumento significante no } \\
\text { trabalho total e na } \\
\text { concentração de AGL e } \\
\text { glicerol }\end{array}$ \\
\hline $\begin{array}{l}\text { Conway et al. } \\
(2003)^{18}\end{array}$ & 9 & M & Treinados & $\begin{array}{l}3 \text { e } 6 \mathrm{mg} / \mathrm{kg} \\
\text { antes e a } \\
45 \mathrm{~min} . \mathrm{de} \\
\text { teste }\end{array}$ & $\begin{array}{l}\text { Cicloergômetro a } 68 \% \text { do } \\
\mathrm{VO}_{2} \text { máx durante } 90 \mathrm{~min} \text {., } \\
\text { seguido de teste a } 80 \% \text { do } \\
\mathrm{VO}_{2} \text { máx durante } 30 \mathrm{~min} \text {. }\end{array}$ & Não & $\begin{array}{l}\text { Não se constatou melhora } \\
\text { no desempenho durante o } \\
\text { teste a } 80 \% \text { do } \mathrm{VO}_{2} \text { máx para } \\
\text { as dosagens de } 3 \text { e } 6 \mathrm{mg} / \mathrm{kg}\end{array}$ \\
\hline
\end{tabular}

Tabela 2. Efeitos ergogênicos da cafeína sobre a performance em exercícios de média e longa duração (continuação).

\begin{tabular}{|c|c|c|c|c|c|c|c|}
\hline Investigadores & $\mathrm{N}$ & Sexo & População & $\begin{array}{l}\text { Dose de } \\
\text { cafeína }\end{array}$ & Tipo de teste & $\begin{array}{l}\text { Efeito } \\
\text { ergogênico? }\end{array}$ & Comentários \\
\hline $\begin{array}{l}\text { Costill et al. } \\
(1978]^{19}\end{array}$ & 9 & $\begin{array}{l}7 \mathrm{M} \\
2 \mathrm{~F}\end{array}$ & Treinados & $330 \mathrm{mg}$ & $\begin{array}{l}\text { Cicloergômetro a } 80 \% \text { do } \\
\mathrm{VO}_{2} \text { máx até a exaustão }\end{array}$ & Sim & $\begin{array}{l}\text { Aumento significante no tempo } \\
\text { de exaustão ( } 21 \mathrm{~min} \text { ), na } \\
\text { concen-tração de AGL e redução } \\
\text { na percepção subjetiva de } \\
\text { esforço. }\end{array}$ \\
\hline $\begin{array}{l}\text { Coxet al. } \\
{[2002]^{21}}\end{array}$ & 12 & M & Treinados & $6 \mathrm{mg} / \mathrm{kg}$ & $\begin{array}{l}\text { Cicloergômetro a } 70 \% \text { do } \\
\mathrm{V0}_{2} \text { máx durante } 120 \mathrm{~min} \text {. }\end{array}$ & Sim & $\begin{array}{l}\text { Melhora significante no } \\
\text { desempenho, independente do } \\
\text { momento da ingestão de } \\
\text { cafeína. }\end{array}$ \\
\hline $\begin{array}{l}\text { Daniels et al. } \\
{[1998]^{22}}\end{array}$ & 10 & $\begin{array}{l}3 \mathrm{M} \\
7 \mathrm{~F}\end{array}$ & Treinados & $6 \mathrm{mg} / \mathrm{kg}$ & $\begin{array}{l}\text { Cicloergômetro a } 65 \% \text { do } \\
\mathrm{V}_{2} \text { máx durante } \\
55 \text { min. }\end{array}$ & Não & $\begin{array}{l}\text { Não se constatou melhora no } \\
\text { desempenho; aumento nas } \\
\text { concentrações de AGL, glicerol, } \\
\text { glicose e lactato }\end{array}$ \\
\hline $\begin{array}{l}\text { Denadai \& } \\
\text { Denadai } \\
{[1998]^{25}}\end{array}$ & 8 & M & Não-treinados & $5 \mathrm{mg} / \mathrm{kg}$ & $\begin{array}{l}\text { Cicloergômetro a } \\
\text { intensidades } \\
\text { equivalentes a } 10 \% \text { abaixo } \\
\text { e acima do limiar } \\
\text { anaeróbio }\end{array}$ & Sim & $\begin{array}{l}\text { Aumento significante no tempo } \\
\text { até exaustão a } 10 \% \text { abaixo do } \\
\text { limiar anaeróbio e redução na } \\
\text { percepção subjetiva de esforço. }\end{array}$ \\
\hline
\end{tabular}


Tabela 2. Efeitos ergogênicos da cafeína sobre a performance em exercícios de média e longa duração (continuação).

\begin{tabular}{|c|c|c|c|c|c|c|c|}
\hline Investigadores & $\mathrm{N}$ & Sexo & População & $\begin{array}{l}\text { Dose de } \\
\text { cafeína }\end{array}$ & Tipo de teste & $\begin{array}{l}\text { Efeito } \\
\text { ergogênico? }\end{array}$ & Comentários \\
\hline $\begin{array}{l}\text { Engels et al. } \\
(1999)^{27}\end{array}$ & 8 & $\begin{array}{l}7 \mathrm{M} \\
1 \mathrm{~F}\end{array}$ & Não-treinados & $5 \mathrm{mg} / \mathrm{kg}$ & $\begin{array}{l}\text { Cicloergômetro a 30\% do } \\
\mathrm{VO}_{2} \text { máx durante } \\
60 \text { min. }\end{array}$ & Não & $\begin{array}{l}\text { Aumento } \\
\text { significante no } \\
\mathrm{VO}_{2} \text { máx, no gasto } \\
\text { energético e na } \\
\text { pressão arterial } \\
\text { sistólica e diastólica }\end{array}$ \\
\hline $\begin{array}{l}\text { Engels \& } \\
\text { Haymes } \\
(1992)^{28}\end{array}$ & 8 & M & Não-treinados & $5 \mathrm{mg} / \mathrm{kg}$ & $\begin{array}{l}\text { Caminhada a } 30 \text { e } 50 \% \text { do } \\
\mathrm{VO}_{2} \text { máx com duração de } \\
60 \text { min. }\end{array}$ & Sim & $\begin{array}{l}\text { Melhora significante } \\
\text { no desempenho e } \\
\text { aumento na } \\
\text { mobilização de AGL }\end{array}$ \\
\hline $\begin{array}{l}\text { Essiget al. } \\
(1980)^{29}\end{array}$ & $?$ & M & Não-treinados & $5 \mathrm{mg} / \mathrm{kg}$ & $\begin{array}{l}\text { Cicloergômetro a } 65.75 \% \\
\text { do } \mathrm{VO}_{2} \text { máx durante } 30 \\
\text { min. }\end{array}$ & Sim & $\begin{array}{l}\text { Melhora significante } \\
\text { no desempenho; } \\
\text { redução na } \\
\text { utilização de } \\
\text { glicogênio ( } 42 \% \text { e } \\
\text { aumento na } \\
\text { mobilização de TGL } \\
\text { muscular }\end{array}$ \\
\hline $\begin{array}{l}\text { Falk et al. } \\
(1989)^{30}\end{array}$ & 23 & M & Treinados & $\begin{array}{l}5 \mathrm{mg} / \mathrm{kg} \\
\text { antes e } \\
2,5 \mathrm{mg} / \mathrm{kg} \\
\text { na } 3^{\circ} \text { e } 5^{\circ} \\
\mathrm{h} \text { marcha }\end{array}$ & $\begin{array}{l}40 \mathrm{~km} \text { de marcha, } \\
\text { seguido de teste em } \\
\text { cicloergômetro a } 90 \% \text { do } \\
\mathrm{V}_{2} \text { máx até a exaustão }\end{array}$ & Não & $\begin{array}{l}\text { Não se constatou } \\
\text { melhora no tempo } \\
\text { de exaustão; } \\
\text { aumento no lactato } \\
\text { após marcha e } \\
\text { cicloergômetro, e } \\
\text { redução na } \\
\text { percepção subjetiva } \\
\text { de esforço }\end{array}$ \\
\hline
\end{tabular}

Tabela 2. Efeitos ergogênicos da cafeína sobre a performance em exercícios de média e longa duração (continuação).

\begin{tabular}{|c|c|c|c|c|c|c|c|}
\hline Investigadores & $\mathrm{N}$ & Sexo & População & $\begin{array}{l}\text { Dose de } \\
\text { cafeína }\end{array}$ & Tipo de teste & $\begin{array}{l}\text { Efeito } \\
\text { ergogênico? }\end{array}$ & Comentários \\
\hline $\begin{array}{l}\text { Ferrauti et al. } \\
(1997)^{32}\end{array}$ & 16 & $\begin{array}{l}8 \mathrm{M} \\
8 \mathrm{~F}\end{array}$ & Treinados & $5 \mathrm{mg} / \mathrm{kg}$ & $\begin{array}{l}\text { Simulação de uma } \\
\text { partida de tênis com } \\
\text { duração de } 240 \mathrm{~min} \text {. }\end{array}$ & Sim & $\begin{array}{l}\text { Melhora significante no } \\
\text { desempenho das mulheres } \\
\text { durante o esforço e no período de } \\
\text { recuperação após o exercício }\end{array}$ \\
\hline $\begin{array}{l}\text { Fisher et al. } \\
{[1986)^{34}}\end{array}$ & 6 & M & Não-treinados & $5 \mathrm{mg} / \mathrm{kg}$ & $\begin{array}{l}\text { Corrida em esteira a } 75 \% \\
\text { do } 0_{2} \text { máx durante } 60 \\
\text { min. }\end{array}$ & Sim & $\begin{array}{l}\text { Melhora significante no } \\
\text { desempenho de corrida e no } \\
\mathrm{V}_{2} \text { máx }(0,17 \mathrm{l} / \mathrm{min}) \text {; aumento na } \\
\text { concentração de lactato, } \\
\text { noraepinefrina e dopamina }\end{array}$ \\
\hline $\begin{array}{l}\text { Flinn et al. } \\
(1990)^{35}\end{array}$ & 9 & M & Não-treinados & $\begin{array}{l}10 \\
\mathrm{mg} / \mathrm{kg}\end{array}$ & $\begin{array}{l}\text { Cicloergômetro } \\
\text { progressivo com } \\
\text { aumento de } 50 \mathrm{~W} \text { a cada } \\
3 \text { min. até a exaustão }\end{array}$ & Sim & $\begin{array}{l}\text { Aumento significante no tempo } \\
\text { de exaustão, no limiar de lactato } \\
\text { e na concentração de AGL }\end{array}$ \\
\hline $\begin{array}{l}\text { Gaesser \& Rich } \\
{[1985)^{36}}\end{array}$ & 8 & M & Não-treinados & $5 \mathrm{mg} / \mathrm{kg}$ & $\begin{array}{l}\text { Teste incremental em } \\
\text { cicloergômetro até } \\
\text { exaustão }\end{array}$ & Não & $\begin{array}{l}\text { Não se constatou melhora no } \\
\text { tempo de exaustão, no } \mathrm{VO}_{2} \text { máx, } \\
\text { ventilação pulmonar e percepção } \\
\text { subjetiva de esforço }\end{array}$ \\
\hline
\end{tabular}


Tabela 2. Efeitos ergogênicos da cafeína sobre a performance em exercícios de média e longa duração (continuação].

\begin{tabular}{|c|c|c|c|c|c|c|c|}
\hline Investigadores & $\mathrm{N}$ & Sexo & População & $\begin{array}{l}\text { Dose de } \\
\text { cafeína }\end{array}$ & Tipo de teste & $\begin{array}{l}\text { Efeito } \\
\text { ergogênico? }\end{array}$ & Comentários \\
\hline $\begin{array}{l}\text { Graham et al. } \\
{[1998]^{42}}\end{array}$ & 9 & M & Não-treinados & $5 \mathrm{mg} / \mathrm{kg}$ & $\begin{array}{l}\text { Corrida em esteira a } 85 \% \\
\text { do } \mathrm{VO}_{2} \text { máx até a exaustão }\end{array}$ & Sim & $\begin{array}{l}\text { Aumentos } \\
\text { significantes no } \\
\text { tempo de exaustão e } \\
\text { na concentração de } \\
\text { epinefrina }\end{array}$ \\
\hline $\begin{array}{l}\text { Graham \& Spriet } \\
(1991)^{44}\end{array}$ & $?$ & M & Treinados & $9 \mathrm{mg} / \mathrm{kg}$ & $\begin{array}{l}\text { Corrida em esteira e } \\
\text { cicloergômetro a } 85 \% \text { do } \\
\mathrm{V}_{2} \text { máx até a exaustão }\end{array}$ & Sim & $\begin{array}{l}\text { Aumentos } \\
\text { significantes no } \\
\text { tempo de exaustão } \\
\text { em ambos os } \\
\text { ergômetros e na } \\
\text { concentração de } \\
\text { epinefrina }\end{array}$ \\
\hline $\begin{array}{l}\text { Graham \& Spriet } \\
(1995)^{45}\end{array}$ & 6 & M & Treinados & $\begin{array}{l}3,6 \text { e } 9 \\
\mathrm{mg} / \mathrm{kg}\end{array}$ & $\begin{array}{l}\text { Corrida em esteira a } 85 \% \\
\text { do } \mathrm{VO}_{2} \text { máx até a exaustão }\end{array}$ & Sim & $\begin{array}{l}\text { Aumentos } \\
\text { significantes no } \\
\text { tempo de corrida } \\
\text { com a ingestão de } 3 \\
\text { e } 6 \mathrm{mg} / \mathrm{kg}\end{array}$ \\
\hline $\begin{array}{l}\text { Greer et al. } \\
(2000)^{46}\end{array}$ & & M & $\begin{array}{l}\text { Não- } \\
\text { treinados }\end{array}$ & $6 \mathrm{mg} / \mathrm{kg}$ & $\begin{array}{l}\text { Cicloergômetro a } 80 \% \text { do } \\
\text { V0 } 0_{2} \text { máx até a exaustão }\end{array}$ & Sim & $\begin{array}{l}\text { Aumentos } \\
\text { significantes no } \\
\text { tempo de exaustão, } \\
\text { na concentração de } \\
\text { epinefrina, glicerol e } \\
\text { cAMP muscular }\end{array}$ \\
\hline $\begin{array}{l}\text { Hunter et al. } \\
(2002]^{47}\end{array}$ & 8 & M & Treinados & $6 \mathrm{mg} / \mathrm{kg}$ & $\begin{array}{l}100 \mathrm{~km} \text { - intermitente em } \\
\text { cicloergômetro } \\
\text { ( } 5 \text { sprint } 1 \mathrm{Km} \text { após } 10 \text {, } \\
32,52,72 \text { e } 99 \mathrm{~km} ; \mathrm{e} 4 \\
\text { sprint } 4 \mathrm{Km} \text { após } 20,40 \text {, } \\
60 \text { e } 80 \mathrm{~km} \text { ] }\end{array}$ & Não & $\begin{array}{l}\text { Não se constatou } \\
\text { melhora na potência } \\
\text { média, no tempo de } \\
\text { realização dos } \\
\text { sprints e no tempo } \\
\text { para completar os } \\
100 \text { km }\end{array}$ \\
\hline
\end{tabular}


Tabela 2. Efeitos ergogênicos da cafeína sobre a performance em exercícios de média e longa duração (continuação).

\begin{tabular}{|c|c|c|c|c|c|c|c|}
\hline Investigadores & $\mathrm{N}$ & Sexo & População & $\begin{array}{l}\text { Dose de } \\
\text { cafeína }\end{array}$ & Tipo de teste & $\begin{array}{l}\text { Efeito } \\
\text { ergogênico? }\end{array}$ & Comentários \\
\hline $\begin{array}{l}\text { Ivy et al. } \\
(1979)^{48}\end{array}$ & 9 & $\begin{array}{l}7 \mathrm{M} \\
2 \mathrm{~F}\end{array}$ & Treinados & $250 \mathrm{mg}$ & $\begin{array}{l}\text { Cicloergômetro a } 60 \% \text { do } \\
\mathrm{VO}_{2} \text { máx durante } 120 \mathrm{~min} \text {. }\end{array}$ & Sim & $\begin{array}{l}\text { Aumento } \\
\text { significante no } \\
\text { trabalho total } \\
{[7,4 \%] \text {, no } \mathrm{VO}_{2} \text { máx }} \\
{[7,3 \% \text { e na }} \\
\text { oxidação de } \\
\text { gorduras [31\%] }\end{array}$ \\
\hline $\begin{array}{l}\text { Kaminsky et al. } \\
(1998)^{55}\end{array}$ & 14 & M & Não-treinados & $\begin{array}{l}243-330 \\
\mathrm{mg}\end{array}$ & $\begin{array}{l}\text { Caminhada/corrida em } \\
\text { esteira a 30,50 e } 70 \% \text { do } \\
\mathrm{VO}_{2} \text { máx }\end{array}$ & Não & $\begin{array}{l}\text { Não se constatou } \\
\text { melhora no } \\
\text { desempenho físico }\end{array}$ \\
\hline $\begin{array}{l}\text { Kovacs et al. } \\
{[1998]^{56}}\end{array}$ & 15 & M & Treinados & $\begin{array}{l}2,3 \text { e } 4,5 \\
\mathrm{mg} / \mathrm{kg}\end{array}$ & $\begin{array}{l}\text { Corrida em esteira a } 75 \% \\
\text { V0 } 0_{2} \text { máx até a exaustão }\end{array}$ & Sim & $\begin{array}{l}\text { Aumento } \\
\text { significante no } \\
\text { tempo de exaustão }\end{array}$ \\
\hline $\begin{array}{l}\text { Macintosh \& } \\
\text { Wright }(1995)^{58}\end{array}$ & 11 & $\begin{array}{l}7 \mathrm{M} \\
4 \mathrm{~F}\end{array}$ & Não-treinados & $6 \mathrm{mg} / \mathrm{kg}$ & $1.500 \mathrm{~m}$ nado livre & Sim & $\begin{array}{l}\text { Redução } \\
\text { significante no } \\
\text { tempo de nado em } \\
\text { prova de } 1.500 \mathrm{~m}\end{array}$ \\
\hline $\begin{array}{l}\text { McNaughton } \\
(1986)^{59}\end{array}$ & 12 & M & Treinados & $\begin{array}{l}10 \text { e } 15 \\
\mathrm{mg} / \mathrm{kg}\end{array}$ & $\begin{array}{l}\text { Corrida em esteira a } 70 \text {. } \\
75 \% \text { do } \mathrm{VO}_{2} \text { máx até a } \\
\text { exaustão }\end{array}$ & Sim & $\begin{array}{l}\text { Aumento } \\
\text { significante no } \\
\text { tempo de exaustão } \\
\text { somente com } \\
\text { ingestão de } 15 \\
\mathrm{mg} / \mathrm{kg}\end{array}$ \\
\hline $\begin{array}{l}\text { Motl et al. } \\
(2003)^{62}\end{array}$ & 16 & M & Não-treinados & $10 \mathrm{mg} / \mathrm{kg}$ & $\begin{array}{l}\text { Cicloergômetro a } 60 \% \text { do } \\
\mathrm{VO}_{2} \text { máx durante } \\
30 \mathrm{~min} .\end{array}$ & Sim & $\begin{array}{l}\text { Aumento } \\
\text { significante no } \\
\text { trabalho total }\end{array}$ \\
\hline
\end{tabular}

Tabela 2. Efeitos ergogênicos da cafeína sobre a performance em exercícios de média e longa duração (continuação)

\begin{tabular}{|c|c|c|c|c|c|c|c|}
\hline Investigadores & $\mathrm{N}$ & Sexo & População & $\begin{array}{l}\text { Dose de } \\
\text { cafeína }\end{array}$ & Tipo de teste & $\begin{array}{l}\text { Efeito } \\
\text { ergogênico? }\end{array}$ & Comentários \\
\hline $\begin{array}{l}\text { Pasman et al. } \\
(1995]^{64}\end{array}$ & 9 & M & Treinados & $\begin{array}{l}5,9 \mathrm{e} \\
13 \\
\mathrm{mg} / \mathrm{kg}\end{array}$ & $\begin{array}{l}\text { Cicloergômetro a 80\% da } \\
\text { carga máxima }(W) \text { até a } \\
\text { exaustão }\end{array}$ & Sim & $\begin{array}{l}\text { Aumento significante no } \\
\text { tempo de exaustão nas } \\
\text { dosagens de } 5,9 \text { e } 13 \mathrm{mg} / \mathrm{kg} \text {, } \\
\text { na concentração de AGL e } \\
\text { glicerol }\end{array}$ \\
\hline $\begin{array}{l}\text { Paula Filho \& } \\
\text { Rodrigues } \\
(1985]^{65}\end{array}$ & 6 & M & Năo-treinados & $500 \mathrm{mg}$ & $\begin{array}{l}\text { Cicloergômetro a } 50,75 \text { e } \\
85 \% \text { do } \mathrm{V}_{2} \text { máx até a } \\
\text { exaustão }\end{array}$ & Sim & $\begin{array}{l}\text { Aumento significante no } \\
\text { tempo de exaustão nas } \\
\text { intensidades de } 50 \text { e } 75 \% \\
\mathrm{VO}_{2} \text { máx }\end{array}$ \\
\hline $\begin{array}{l}\text { Powers et al. } \\
(1997)^{6 ?}\end{array}$ & $?$ & M & Treinados & $5 \mathrm{mg} / \mathrm{kg}$ & $\begin{array}{l}\text { Cicloergômetro progressivo } \\
\text { com aumento de } 30 \mathrm{~W} \text { a cada } \\
3 \text { min. até a exaustão }\end{array}$ & Não & $\begin{array}{l}\text { Não se constatou melhora no } \\
\text { tempo de exaustão; aumento } \\
\text { significante na concentração } \\
\text { de AGL e glicerol }\end{array}$ \\
\hline $\begin{array}{l}\text { Rodrigues et al. } \\
(1990)^{70}\end{array}$ & 6 & $M$ & Treinados & $5 \mathrm{mg} / \mathrm{kg}$ & $\begin{array}{l}\text { Cicloergômetro progressivo } \\
\text { de } 3 \text { min. à } 300 \text { e } 600 \\
\text { kg.m.min }{ }^{-1} \text {, seguido de } \\
\text { incremento de } 1200 \\
\text { kg.m.min }{ }^{-1} \text {, até a exaustão }\end{array}$ & Não & $\begin{array}{l}\text { Não se constatou melhora no } \\
\text { tempo de exaustão, } \mathrm{V}_{2} \mathrm{máx} \text {, } \\
\text { ventilação pulmonar; redução } \\
\text { significante na percepção } \\
\text { subjetiva de esforço }\end{array}$ \\
\hline
\end{tabular}


Tabela 2. Efeitos ergogênicos da cafeína sobre a performance em exercícios de média e longa duração (continuação).

\begin{tabular}{|c|c|c|c|c|c|c|c|}
\hline Investigadores & $\mathrm{N}$ & Sexo & População & $\begin{array}{l}\text { Dose de } \\
\text { cafeína }\end{array}$ & Tipo de teste & $\begin{array}{l}\text { Efeito } \\
\text { ergogênico? }\end{array}$ & Comentários \\
\hline $\begin{array}{l}\text { Ryu et al. } \\
{[2001]^{73}}\end{array}$ & 14 & M & Treinados & $5 \mathrm{mg} / \mathrm{kg}$ & $\begin{array}{l}\text { Cicloergômetro a } 60 \% \text { do } \\
\text { vo }_{2} \text { máx durante } 45 \text { min., } \\
\text { seguido de teste máximo a } \\
80 \% \text { do } \mathrm{VO}_{2} \text { máx até a } \\
\text { exaustão }\end{array}$ & Sim & $\begin{array}{l}\text { Aumento significante no } \\
\text { tempo de exaustão, na } \\
\text { concentração AGL, glicerol e } \\
\text { lactato; redução na razão de } \\
\text { troca respiratória }\end{array}$ \\
\hline $\begin{array}{l}\text { Sasaki et al. } \\
(1987)^{74}\end{array}$ & 5 & M & Treinados & $300 \mathrm{mg}$ & $\begin{array}{l}\text { Corrida em esteira a } 80 \% \\
\mathrm{VO}_{2} \text { máx até a exaustão }\end{array}$ & Sim & $\begin{array}{l}\text { Aumento significante no } \\
\text { tempo de corrida até a } \\
\text { exaustão [aprox. 35\%] }\end{array}$ \\
\hline $\begin{array}{l}\text { Sasaki et al. } \\
(1987)^{75}\end{array}$ & 7 & M & Não-treinados & 800 mg & $\begin{array}{l}\text { Corrida progressiva em } \\
\text { esteira a } 62-67 \% \text { do } \mathrm{VO}_{2} \text { máx } \\
\text { até a exaustão }\end{array}$ & Não & $\begin{array}{l}\text { Não se constatou melhora no } \\
\text { tempo de corrida até a } \\
\text { exaustão }\end{array}$ \\
\hline Spriet $[1992]^{79}$ & 8 & M & Treinados & $9 \mathrm{mg} / \mathrm{kg}$ & $\begin{array}{l}\text { Cicloergômetro a } 80 \% \text { do } \\
\mathrm{VO}_{2} \text { máx até a exaustão }\end{array}$ & Sim & $\begin{array}{l}\text { Aumento significante no } \\
\text { tempo de exaustão ( } 27 \% \text { ) e na } \\
\text { concentração de epinefrina; } \\
\text { redução na depleção de } \\
\text { glicogênio muscular [ } 55 \% \text { ] }\end{array}$ \\
\hline
\end{tabular}

Tabela 2. Efeitos ergogênicos da cafeína sobre a performance em exercícios de média e longa duração (continuação).

\begin{tabular}{|c|c|c|c|c|c|c|c|}
\hline Investigadores & $\mathrm{N}$ & Sexo & População & $\begin{array}{l}\text { Dose de } \\
\text { cafeína }\end{array}$ & Tipo de teste & $\begin{array}{l}\text { Efeito } \\
\text { ergogênico? }\end{array}$ & Comentários \\
\hline $\begin{array}{l}\text { Tarnopolsky et } \\
\text { al. }(1989)^{82}\end{array}$ & 6 & M & Treinados & $6 \mathrm{mg} / \mathrm{kg}$ & $\begin{array}{l}\text { Corrida em esteira a } 70 \% \text { do } \\
\mathrm{VO}_{2} \text { máx durante } 90 \mathrm{~min} \text {. }\end{array}$ & Não & $\begin{array}{l}\text { Não se constatou melhora } \\
\text { na função neuromuscular, } \\
\text { na percepção subjetiva de } \\
\text { esforço, no } \mathrm{VO}_{2} \text { máx; na } \\
\text { concentração de glicose, } \\
\text { lactato e catecolanimas }\end{array}$ \\
\hline $\begin{array}{l}\text { Trice \& Haynes } \\
(1995)^{83}\end{array}$ & 8 & M & Treinados & $5 \mathrm{mg} / \mathrm{kg}$ & $\begin{array}{l}\text { Cicloergômetro a } 85-90 \% \text { do } \\
\text { vo }_{2} \text { máx com duração total de } \\
120 \text { min. ( } 4 \text { × } 30 \text { min.) e } 5 \text { min. } \\
\text { repouso entre cada série }\end{array}$ & Sim & $\begin{array}{l}\text { Melhora significante no } \\
\text { desempenho; aumento na } \\
\text { concentração de AGL }\end{array}$ \\
\hline $\begin{array}{l}\text { Van Baak \& } \\
\text { Saris }(2000)^{84}\end{array}$ & 15 & M & Não-treinados & $5 \mathrm{mg} / \mathrm{kg}$ & $\begin{array}{l}\text { Cicloergômetro progressivo } \\
\text { com aumento de } 50 \mathrm{~W} \text { a cada } \\
2,5 \text { min. até se atingir a } \\
\text { freqüência cardíaca de } 160 \\
\text { bpm. A partir daí, incrementos } \\
\text { de } 25 \mathrm{~W} \text { a cada } 2,5 \text { min. até a } \\
\text { exaustão }\end{array}$ & Sim & $\begin{array}{l}\text { Aumento significante no } \\
\text { tempo de exaustão }\end{array}$ \\
\hline
\end{tabular}


Tabela 2. Efeitos ergogênicos da cafeína sobre a performance em exercícios de média e longa duração (continuação).

\begin{tabular}{|c|c|c|c|c|c|c|c|}
\hline Investigadores & $\mathrm{N}$ & Sexo & População & $\begin{array}{l}\text { Dose de } \\
\text { cafeína }\end{array}$ & Tipo de teste & $\begin{array}{l}\text { Efeito } \\
\text { ergogênico? }\end{array}$ & Comentários \\
\hline $\begin{array}{l}\text { Van Soeren \& } \\
\text { Graham } \\
(1993)^{86}\end{array}$ & 6 & M & Treinados & $6 \mathrm{mg} / \mathrm{kg}$ & $\begin{array}{l}\text { Cicloergômetro a } 80-85 \% \\
\text { do } \mathrm{VO}_{2} \text { máx até a exaustão }\end{array}$ & Sim & $\begin{array}{l}\text { Aumento significante no } \\
\text { tempo de exaustão, na } \\
\text { concentração de AGL e } \\
\text { epinefrina }\end{array}$ \\
\hline $\begin{array}{l}\text { Van Soeren et al. } \\
(1993)^{8 ?}\end{array}$ & 14 & M & Não-treinados & $5 \mathrm{mg} / \mathrm{kg}$ & $\begin{array}{l}\text { Cicloergômetro a } 50 \% \text { do } \\
\mathrm{VO}_{2} \text { máx durante } 60 \mathrm{~min} \text {. }\end{array}$ & Sim & $\begin{array}{l}\text { Melhora significante no } \\
\text { desempenho; aumento na } \\
\text { concentração de epinefrina } \\
\text { em usuários e não-usuários } \\
\text { habituais de cafeína }\end{array}$ \\
\hline $\begin{array}{l}\text { Vanakoski et al. } \\
(1998)^{88}\end{array}$ & $?$ & M & Treinados & $7 \mathrm{mg} / \mathrm{kg}$ & $\begin{array}{l}\text { Cicloergômetro a } 65 \% \text { da } \\
\text { FCmax durante } 45 \mathrm{~min} \text {. }\end{array}$ & Não & $\begin{array}{l}\text { Não se constatou melhora no } \\
\text { desempenho, nem } \\
\text { modificações na FC e na } \\
\text { concentração de Lactato }\end{array}$ \\
\hline $\begin{array}{l}\text { Wemple et al. } \\
(1997)^{91}\end{array}$ & $\begin{array}{l}4 \\
2\end{array}$ & $\begin{array}{l}M \\
F\end{array}$ & Treinados & $\begin{array}{l}8,7 \\
\mathrm{mg} / \mathrm{kg}\end{array}$ & $\begin{array}{l}\text { Cicloergômetro a } 60 \% \text { do } \\
\mathrm{VO}_{2} \text { máx durante } 180 \mathrm{~min} . \text {, } \\
\text { seguido de teste a } 85 \% \text { do } \\
\mathrm{VO}_{2} \text { máx até a exaustão }\end{array}$ & Nào & $\begin{array}{l}\text { Não se constatou melhora no } \\
\text { tempo de exaustão; } \\
\text { manutenção dos níveis } \\
\text { plasmáticos de catecolaminas }\end{array}$ \\
\hline
\end{tabular}

Pesquisas recentes têm indicado que a ação da cafeína nos estoques de glicogênio parece ocorrer independentemente da ação da epinefrina (76). Assim sendo, o que tem sido observado por alguns pesquisadores é que a ação da cafeína parece estar diretamente relacionada à antagonização dos receptores de adenosina que normalmente inibem a mobilização dos ácidos graxos livres (AGLs) $(24,46)$.

Aparentemente, este fator poderia contribuir no aumento da oxidação da gordura muscular, reduzindo a oxidação de $\mathrm{CHO}$ e, dessa forma, melhorar o rendimento nos exercícios físicos prolongados em consequiência de uma redução na disponibilidade de CHO (43), visto que sua acentuada depleção tem sido apontada como um fator limitante do desempenho físico (50).

Entretanto, essa economia na utilização de $\mathrm{CHO}$ (glicogênio muscular) durante o exercício físico prolongado, em função da ingestão de cafeína, parece nem sempre ocorrer $(46,57)$, principalmente se as reservas de glicogênio muscular se encontrarem altas (57).

Recentemente, Graham et al. (41), examinando o efeito da cafeína sobre o metabolismo da gordura e do carboidrato no músculo de humanos através de biópsia, evidenciaram uma possível ação direta da cafeína sobre o sistema nervoso simpático, entretanto, não foi constatada nenhuma alteração no metabolismo de gordura e carboidrato. Assim sendo, parece que outros tecidos estão envolvidos na ação da cafeína, contribuindo para a melhora no desempenho em exercícios de média e longa duração $(41,46)$.

As evidências vêm contribuir para uma indefinição ainda maior em relação às hipóteses da ação da cafeína sobre o metabolismo das gorduras e dos carboidratos, indicando a necessidade da realização de novas pesquisas, no sentido de um esclarecimento com relação a ação desta substância sobre o metabolismo aeróbio.

Em uma revisão recente, Altimari et al. (1) constataram que o uso da cafeína em exercícios físicos de média e longa duração pode ser capaz de promover uma melhoria na eficiência metabólica dos sistemas energéticos durante o esforço, contribuindo para melhoria da performance. Os resultados encontrados a partir desta revisão demonstraram que $75 \%$ dos trabalhos revisados apresentaram efeito ergogênico, além de diferentes respostas metabólicas e fisiológicas após a administração desta substância. Esses mesmos autores observaram que a dosagem de cafeína é fator determinante na melhora da performance, pois o desencadeamento das respostas fisiológicas e 
metabólicas parece estar atrelado à quantidade ingerida. Assim, embora doses de cafeína entre 3 e 10 $\mathrm{mg} / \mathrm{kg}$ de peso corporal possam melhorar a performance, o intervalo ótimo sugerido é de 3 a $6 \mathrm{mg} / \mathrm{kg}$ (1). Na Figura 3 são apresentados os dados de Altimari et al. (2000), que mostram os efeitos das diferentes dosagens de cafeína utilizadas nos estudos que investigaram a eficiência ergogênica desta substância em diferentes modalidades de exercício físico.

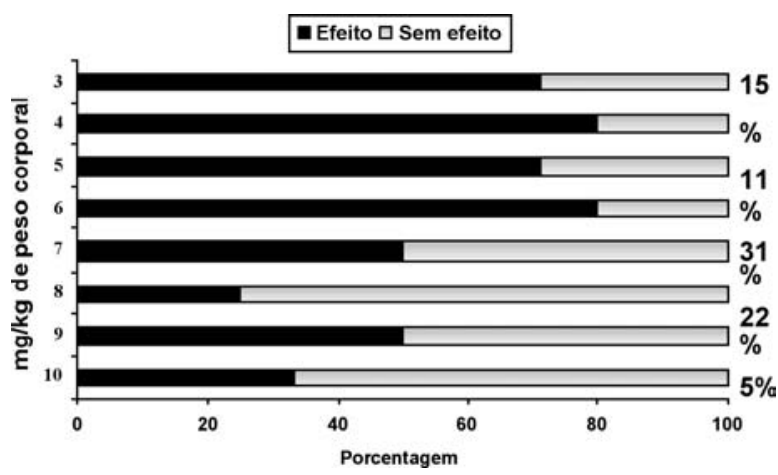

Figura 3. Efeito das diferentes concentrações de cafeína utilizadas nos estudos que investigaram a eficiência ergogênica desta substância em diferentes modalidades de exercícios (Altimari et al., 1).

Esses achados são confirmados por outros trabalhos publicados recentemente, que apontam a cafeína como um eficiente agente ergogênico em exercícios físicos de média e longa duração $(11,40,52,53)$. A utilização desta substância tem gerado uma série de dúvidas acerca da sua possível ação diurética, uma vez que acarretaria aumento no volume de urina, e, portanto, uma maior perda hídrica, o que poderia afetar negativamente a performance, particularmente nos esforços de longa duração.

Entretanto, o suposto efeito diurético provocado pelo uso dessa substância não tem sido confirmado na prática $(1,5)$.

Alguns estudos têm demonstrado que a ingestão de pequenas doses de cafeína antes de exercícios físicos prolongados não parece afetar negativamente a performance, visto que o comprometimento do estado de hidratação corporal parece estar relacionado somente ao emprego de mega-doses desta substância $(5,69,90,91)$.

\section{EFEITOS COLATERAIS}

O modelo atual de esporte tem contribuído para uma busca incessante de resultados, o que tem levado atletas à utilização de diferentes substâncias, desconsiderando os conceitos éticos e de saúde. Ao que parece, o consumo de cafeína objetivando a melhoria da performance, tem sido feito de forma indiscriminada e sem os cuidados necessários.

A ingestão de altas doses de cafeína $(10-15 \mathrm{mg} / \mathrm{kg}$ de peso corporal) não é recomendada, pois os níveis plasmáticos de cafeína podem alcançar valores tóxicos de até $200 \mu \mathrm{m}$ (31). Os efeitos colaterais causados pela ingestão de cafeína ocorrem em maior proporção em pessoas suscetíveis e que utilizam esta substância em excesso $(14,76)$.

A cafeína pode prejudicar a estabilidade de membros superiores, induzindo-os a trepidez e tremor, resultantes da tensão muscular crônica $(14,77)$, e ainda induzir a insônia, nervosismo, irritabilidade, ansiedade, náuseas e a desconforto gastrointestinal $(49,80)$. Os problemas estomacais podem ser agravados por quem já apresenta tendência para gastrite ou úlcera, principalmente quando ingerida em jejum $(14,76)$. Todas as possibilidades citadas anteriormente devem ser consideradas quando da utilização desta substância por parte de atletas, pois tais ocorrências poderão influenciar negativamente a performance atlética (2).

\section{CONSIDERAÇÕES FINAIS}

Os achados apontam a cafeína como um eficiente agente ergogênico em exercícios físicos de média e longa duração. O efeito ergogênico da cafeína sobre a performance tem sido evidenciado após a ingestão aguda de doses de cafeína entre 3 e $6 \mathrm{mg} / \mathrm{kg}$ de peso corporal. Contudo, ainda não parece estar claro quais os mecanismos de ação da cafeína que estariam envolvidos na melhoria da performance em exercícios prolongados, uma vez que estudos recentes têm apresentado resultados conflitantes com as hipóteses até aqui sustentadas, indicando a necessidade de novas pesquisas no sentido de esclarecer a verdadeira ação desta substância sobre o metabolismo aeróbio. Com relação ao suposto efeito diurético provocado pelo uso da cafeína, nada tem sido confirmado na prática. Acredita-se que o comprometimento do estado de hidratação corporal possa estar relacionado somente ao emprego de mega-doses desta substância. 
As evidências do efeito ergogênico da cafeína sobre a performance em exercícios de média e longa duração, associadas à recente retirada da cafeína da lista de substâncias proibidas pela WADA, possivelmente implicará em um aumento considerável no uso desta substância por parte dos atletas. Dessa forma, é necessário tomar alguns cuidados quando da utilização desta substância, uma vez que a ingestão desorientada pode contribuir para o aparecimento de efeitos colaterais, que podem influenciar negativamente a performance atlética.

\section{Agradecimentos}

Os autores agradecem à CAPES e ao CNPq pelo apoio financeiro e bolsas outorgadas.

\section{CORRESPONDÊNCIA}

\section{Leandro Altimari}

Faculdade de Ciências Farmacêuticas

Departamento de Alimentos e Nutrição Experimental Universidade de São Paulo

Av. Prof. Lineu Prestes, 580, Cidade Universitária

CEP 05508-900 - São Paulo, SP

Brasil

lraltimari@hotmail.com

\section{REFERÊNCIAS}

1. Altimari LR, Cyrino ES, Zucas SM, Burini RC (2000). Efeitos ergogênicos da cafeína sobre o desempenho físico. Paul J Phys Educ 14: 141-58.

2. Altimari LR, Cyrino ES, Zucas SM, Okano AH, Burini RC (2001). Cafeína: ergogênico nutricional no esporte. Braz J Mov Sci 9: 57-64.

3. Alves MN, Ferrari-Auarek WM, Pinto KMC, Sá KR, Viveiros JP, Pereira HAA, Ribeiro AM, Rodrigues LOC (1995). Effects of caffeine on tryptophan on rectal temperature, metabolism, total exercise time, rate of perceived exertion and heart rate. Braz J Med Biol Res 28: 705-9.

4. Applegate E (1999). Effective nutritional ergogenic aids. Int J Sports Nutr 9: 229-39.

5. Armstrong LE (2002). Caffeine, body fluid-electrolyte balance, and exercise performance. Int J Sport Nutr Exerc Metab 12: 189-206.

6. Bell DG, Jacobs I, Zamecnik J (1998). Effects of caffeine, efedrine and their combination on time to exhaustion during high-intensity exercise. Eur J Appl Physiol Occup Physiol 77: 427-33.

7. Bell DG \& Mclellan TM (2003). Effect of repeated caffeine ingestion on repeated exhaustive exercise endurance. Med Sci Sports Exerc 35: 1348-54.

8. Bellet S, Kershbaum A, Fink EM (1968). Response of free fatty acids to coffee and caffeine. Metabolism 17: 702-7.

9. Berglund B \& Hemmingsson P (1982). Effects of caffeine ingestion on exercise performance at low and high altitudes in cross-country skiers. Int J Sports Med 3: 234-6.

10. Butts NK \& Crowell D (1985). Effect of caffeine ingestion on cardiorespiratory endurance in men and women. Res $Q$ Exerc Sport 56: 301-5.

11. Braga LC \& Alves MP (2000). A cafeína como recurso ergogênico nos exercícios de endurance. Braz J Mov Sci 8: 33-7.

12. Bucci LR (2000). Selected herbals and human exercise performance. Am J Clin Nutr 200072 (suppl): 624S-36S.

13. Cadarette B, Levine L, Berube C, Posnerb B, Evans W (1983). Effects of varied dosages of caffeine on endurance exercise to fatigue. In: HG Knuttgen, J Vogel, J Poortmans(Eds). Biochemistry of Exercise. Champaign: Human Kinetics Publishers, 871-6.

14. Clarkson PM (1993). Nutritional ergogenic aids: caffeine. Int J Sports Nutr 3: 103-11.

15. Casal DC \& Leon, AS (1985). Failure of caffeine to affect substrate utilization during prolonged running. Med Sci Sports Exerc 17: 174-9.

16. Cohen BS, Nelson AG, Prevost MC, Thompson GD, Marx BD, Morris GS (1996). Effects of caffeine ingestion on endurance racing in heat and humidity. Eur J Appl Physiol Occup Physiol 73: 358-63.

17. Cole KJ, Costill DL, Starling RD, Goodpaster BH, Trappe SW, Fink WJ (1996). Effects of caffeine ingestion on perception of effort and subsequent work production. Int J Sports Nutr 6: 14-23.

18. Conway KJ, Orr R, Stannard SR (2003). Effect of a divided caffeine dose on endurance cycling performance, postexercise urinary caffeine concentration, and plasma paraxanthine. J Appl Physiol 94: 1557-62.

19. Costill DL, Dalsky G, Fink W (1978). Effects of caffeine ingestion on metabolism and exercise performance. Med 
Sci Sports Exerc 10: 155-8.

20. Coyle EF (2004). Fluid and fuel intake during exercise. $J$ Sports Sci 22: 39-55.

21. Cox GR, Desbrow B, Montgomery PG, Anderson ME, Bruce CR, Macrides TA, Martin, DT, Moquin A, Roberts A, Hawley JA, Burke LM (2002). Effect of different protocols of caffeine intake on metabolism and endurance performance. J Appl Physiol. 93: 990-9.

22. Daniels JW, Molé PA, Shaffrath JD, Stebbins CL (1998). Effects of caffeine on blood pressure, heart rate, and forearm blood flow during dynamic leg exercise. J Appl Physiol 85: 154-9.

23. Davis JM \& Bailey SP (1997). Possible mechanisms of central nervous system fatigue during exercise. Med Sci Sports Exerc 29: 45-57.

24. Davis JM, Zhao Z, Stock HS, Mehl KA, Buggy J, Hand GA (2003). Central nervous system effects of caffeine and adenosine on fatigue. Am J Physiol Regul Integr Comp Physiol 284: 399-404.

25. Denadai BS \& Denadai ML (1998). Effects of caffeine on time to exhaustion in exercise performance below and above the anaerobic threshold. Braz J Med Biol Res 31: 5815.

26. Duthel JM, Vallon JJ, Martin G, Ferret JM, Mathieu R, Videman R (1991). Caffeine and sport: role of physical exercise. Med Sci Sports Exerc 23: 980-5.

27. Engels HJ, Wirth JC, Celik S, Dorsey JL (1999). Influence of caffeine on metabolic and cardiovascular functions during sustained light intensity cycling and at rest. Int $J$ Sports Nutr 9: 361-70.

28. Engels HJ \& Haymes EM (1992). Caffeine ingestion on metabolic responses to prolonged walking in sedentary males. Int J Sports Nutr 2: 386-96.

29. Essig DA, Costill DL, Van Handel PJ (1980). Effects of caffeine ingestion on utilization of muscle glycogen and lipid during leg ergometer cycling. Int J Sports Med 1: 86-90.

30. Falk B, Burstein R, Ashkenazi I, Spilberg O, Alter J, Zylber-Katz E, Rubinstein A, Bashan N, Shapiro Y (1989). The effect of caffeine ingestion on physical performance after prolonged exercise. Eur J Appl Physiol Occup Physiol 59: 168-73.

31. Ferdholm BB (1985). On the mechanism of action of theophilline and caffeine. Acta Med Scand 217: 149-153.

32. Ferrauti A, Weber K, Struder HK (1997). Metabolic and ergogenic effects of carbohydrate and caffeine. J Sports Med Phys Fitness 37: 258-66.

33. Fillmore CM, Bartoli L, Bach R, Park Y (1999). Nutrition and dietary supplements. Phys Med Rehabil Clin N Am 10: 673-703.

34. Fisher SM, Mcmurray RG, Berry M, Mar MH, Forsythe WA (1986). Influence of caffeine on exercise performance in habitual caffeine users. In J Sports Med 7: 276-80.

35. Flinn S, Gregory J, Mcnaughton LR, Tristram S, Davies $P$ (1990). Caffeine ingestion prior to incremental cycling to exhaustion in recreational cyclists. Int J Sports Med 11: 18893.

36. Gaesser GA. \& Rich RG (1985). Influence of caffeine on blood lactate response during incremental exercise. Int $J$ Sports Med 6: 207-11.

37. George AJ (2000). Central nervous system stimulants. Baillieres Best Pract Res Clin Endocrinol Metab 14: 79-88.

38. Goabduff T, Dreano Y, Guilois B, Menez JF, Berthou F
(1996). Induction of liver and kidney CYP 1A1/1A2 by caffeine in rat. Biochem Pharmacol 52: 1915-9.

39. Graham TE (2001). Caffeine, coffee and ephedrine: impact on exercise performance and metabolism. Can J Appl Physiol 26 (suppl): 103S-19S.

40. Graham TE (2001). Caffeine and exercise: metabolism, endurance and performance. Sports Med 31: 785-807.

41. Graham TE, Helge JW, Maclean DA, Kiens B, Richter EA (2000). Caffeine ingestion does not alter carbohydrate or fat metabolism in human skeletal muscle during exercise. $J$ Physiol 15: 837-47.

42. Graham TE, Hibbert E, Sathasivam P (1998). Metabolic and exercise endurance effects of coffee and caffeine ingestion. J Appl Physiol 85: 883-9.

43. Graham TE, Rush JW, Van Soeren MH (1994). Caffeine and exercise: metabolism and performance. Can J Appl Physiol 19: 111-38.

44. Graham TE \& Spriet LL (1991). Performance and metabolic responses to a high caffeine dose during prolonged exercise. J Appl Physiol 71: 2292-8.

45. Graham TE \& Spriet LL (1995). Metabolic, catecholamine and exercise performance responses to varying doses of caffeine. J Appl Physiol 78: 867-74.

46. Greer F, Friars D, Graham TE (2000). Comparison of caffeine and theophylline ingestion: exercise metabolism and endurance. J Appl Physiol 89: 1837-44.

47. Hunter AM, St Clair Gibson A, Collins M, Lambert M, Noakes TD (2002). Caffeine ingestion does not alter performance during a 100-km cycling time-trial performance. Int J Sport Nutr Exerc Metab 12: 438-52.

48. Ivy JL, Costill DL, Fink WJ, Lower RW (1979). Influence of caffeine and carbohydrate feedings on endurance performance. Med Sci Sports Exerc 11: 6-11.

49. Jacobson BH \& Kulling FA (1989). Health and ergogenic effects of caffeine. Br J Sports Med 23: 34-40.

50. Jeukendrup AE \& Jentjens R (2000). Oxidation of carbohydrate feedings during prolonged exercise. Sports Med 29: 407-426.

51. Jeukendrup AE \& Martin J (2001). Improving cycling performance: how should we spend our time and money. Sports Med 31: 559-69.

52. Juhn MS (2002). Ergogenic aids in aerobic activity. Curr Sports Med Rep 1: 233-8.

53. Juhn MS (2003). Popular sports supplements and ergogenic aids. Sports Med 33: 921-39.

54. Kalow W \& Tang B (1993). The use of caffeine for enzymatic assays: A critical appraisal. Clin Pharmacol Ther 53: 503-14.

55. Kaminsky LA, Martin CA, Whaley MH (1998). Caffeine consumption habits do not influence the exercise blood pressure response following caffeine ingestion. J Sports Med Phys Fitness 38: 53-8.

56. Kovacs EM, Stegen JHCH, Brouns F (1998). Effect of caffeinated drinks on substrate metabolism, caffeine excretion, and performance. J Appl Physiol 85: 709-15.

57. Laurent D, Schneider KE, Prusaczyk WK, Franklin C, Vogel SM, Krssak M, Petersen KF, Goforth HW, Shulman GI (2000). Effects of caffeine on muscle glycogen utilization and the neuroendocrine axis during exercise. J Clin Endocrinol Metab 85: 2167-69.

58. MacIntoshi BR \& Wright BM (1995). Caffeine ingestion and performance of a 1.500 meter swim. Can J Appl Physiol 
20: 168-77.

59. McNaughton LR (1986). The influence of caffeine ingestion on incremental treadmill running. Br J Sports Med 20: 109-12.

60. Maughan RJ (1999). Nutritional ergogenic aids and exercise performance. Nutr Res Rev 12: 255-280.

61. Maughan R (2002). The athlete's diet: nutritional goals and dietary strategies. Proc Nutr Soc 61: 87-96.

62. Motl RW, O'connor PJ, Dishman RK (2003). Effect of caffeine on perceptions of leg muscle pain during moderate intensity cycling exercise. J Pain 4: 316-21.

63. Paluska SA (2003). Caffeine and exercise. Curr Sports Med Rep 2: 213-9.

64. Pasman WJ, Van Baak MA, Jeukendrup AE, De Haan A (1995). The effect of different dosages of caffeine on endurance performance time. Int J Sports Med 16: 225-30.

65. Paula Filho U, Rodrigues LOC (1985). Estudo do efeito da cafeína em diferentes níveis de exercício. Braz J Sci Sports 6: 139-46.

66. Pipe A \& Ayotte C (2002). Nutritional supplements and doping. Clin J Sport Med 2002 12: 245-9.

67. Powers SK, Byrd RJ, Tulley R, Callender T (1983). Effects of caffeine ingestion on metabolism and performance during graded exercise. Eur J Appl Physiol Occup Physiol 50: 301-7.

68. Rachima-Maoz C, Peleg E, Rosenthal T (1998). The effects of caffeine on ambulatory blood pressure in hypertensive patients. Am J Hypertens 11: 1426-32.

69. Rehrer NJ (2001). Fluid and electrolyte balance in ultraendurance sport. Sports Med 31: 701-15.

70. Rodrigues LO, Russo AK, Silva AC, Picarro IC, Silva FR, Zogaib PS, Soares DD (1990). Effects of caffeine on the rate of perceived exertion. Braz J Med Biol Res 23: 965-8.

71. Rogers CC (1985). Caffeine. Sports Med 13: 38-40.

72. Roy B, Tarnopolsky M, Macdougall JD, Hicks A (1994). Caffeine and neuromuscular fatigue in endurance athletes. Can J Appl Physiol 19: S41.

73. Ryu S, Choi SK, Joung SS, Suh H, Cha YS, Lee S, Lim K (2001). Caffeine as a lipolytic food component increases endurance performance in rats and athletes. J Nutr Sci Vitaminol 47: 139-46.

74. Sasaki H, Maeda J, Usui S, Ishiko T (1987). Effect of caffeine ingestion on performance of prolonged strenuous running. Int J Sports Med 8: 261-5.

75. Sasaki H, Takaoka I, Ishiko I (1987). Effect of sucrose or caffeine ingestion on running performance and biochemical responses to of endurance running. Int J Sports Med 8: 203-7.

76. Sinclair CJD \& Geiger JD (2000). Caffeine use in sport: a pharmacological review. J Sports Med Phys Fitness 40: 71-9.

77. Spriet LL (1995). Caffeine and performance. Int J Sports Nutr 5: 84-99.

78. Spriet LL \& Gibala MJ (2004). Nutritional strategies to influence adaptations to training. Sports Sci 22: 127-41.

79. Spriet LL, Maclean DA, Dyck DJ, Hultman E, Cederblad G, Graham TE (1992). Caffeine ingestion and muscle metabolism during prolonged exercise in humans. Am J Physiol 262: E891-8.

80. Stephenson PE (1977). Physiologic and psychotropic effects of caffeine on man. J Am Diet Assoc 71: 240-7.

81. Tarnopolsky MA (1994). Caffeine and endurance performance. Sports Med 18: 109-25.
82. Tarnopolsky MA, Atkinson SA, Macdougall JD, Sale DG, Sutton JR (1989). Physiological responses to caffeine during endurance running in habitual caffeine users. Med Sci Sports Exerc 21: 418-24.

83. Trice I \& Haymes EM (1995). Effects of caffeine ingestion on exercise induced changes during high-intensity, intermittent exercise. Int J Sports Nutr 5: 37-44.

84. Van Baak MA \& Saris WHM (2000). The effect of caffeine on endurance performance after nonselective $\beta$-adrenergic blockade. Med Sci Sports Exerc 32: 499-503.

85. Van Nieuwenhoven MA, Brummer RJM, Brouns F (2000). Gastrointestinal function during exercise: comparison of water, sport drink, and sports drink with caffeine. J Appl Physiol 89: 1079-85.

86. Van Soeren MH \& Graham TE (1998). Effects on metabolism, exercise endurance and catecholamine responses after withdrawal. J Appl Physiol 85: 1493-501.

87. Van Soeren MH, Sathasivam P, Spriet LL, Graham TE (1993). Caffeine metabolism and epinephrine responses during exercise in users and non-users. J Appl Physiol 75: 805-12.

88. Vanakoski J, Kosunen V, Meririnne E, Seppala T (1998). Creatine and caffeine in anaerobic and aerobic exercise: effects on physical performance and pharmacokinetic considerations. Int J Clin Pharmacol Ther 36: 258-62.

89. Wang Y, Lau CE (1998). Caffeine has similar pharmacokinetics and behavioral effects via the i.p. and p.o. routes of administration. Pharmacol Biochem Behav 60: 271-78.

90. Wemple RD, Lamb DR, Bronstein AC (1994). Caffeine ingested in a fluid replacement beverage during prolonged exercise does not cause diuresis. Med Sci Sports Exerc 26 (suppl): S204.

91. Wemple RD, Lamb DR, Mckeever KH (1997). Caffeine vs caffeine-free sports drinks: effects on urine production at rest and during prolonged exercise. Int J Sports Med 18: 40-6.

92. Yamada Y, Nakazato Y, Ohga A (1989). The mode of action of caffeine on catecholamine release from perfused adrenal glands of cat. Br J Pharmacol 98: 351-6.

93. World Anti Doping Agency (WADA) (2004). Capturado em 30 mar. On line. Disponível via Internet http://www.wada-ama.org/en/t1.asp. 